\title{
Application of Biotechnology as a Breeding Tool in Crop Improvement for Drought Tolerances
}

\author{
Birhanu Babiye* \\ Ethiopian institute of agricultural research National agricultural biotechnology research center Plant \\ biotechnology program
}

*Corresponding Author: Birhanu Babiye, Ethiopian institute of agricultural research National agricultural biotechnology research center Plant biotechnology program

\begin{abstract}
Plant breeding has to be considered one of the longest and continuous activities conducted by human for improvement of crops for different trait, drought stress tolerance crop breeding is one of human breeding objective and it is one of the major yield constraints for different type of crops. Traditionally for developing drought tolerant cultivars conventional based selection is practiced. Although this approach is effective for several years but conventional methods are time consuming and labour intensive. Biotechnology tool such as Identification of drought related quantitative trait loci (QTLs) coupled with marker assisted selection, Transgenic and "omics" technologies promise to make progress in breeding for drought tolerance through a more fundamental understanding of underlying mechanisms of drought tolerance and identifying potential candidate genes so in these review cover both conventional and modern biotechnology tool that are used for drought tolerance crop improvement and the new approaches provide opportunities to direct the continued breeding of genotypes giving stable yields under drought stress.
\end{abstract}

Keywords: heat; climate change; crop genotypes; morphology; physiology; stress susceptibility

\section{INTRODUCTION}

Plant breeding has to be considered one of the longest, continuous activities conducted by humans and the evolution of the human civilizations paralleled with the successes of plant breeding. Plant breading have different role or objective that improve plant productivity for various purpose those are breading for Drought tolerances improvement of crop, Breeding for Salt tolerance improvement of crop, Breeding for disease resistance improvement of crop, Breeding for insect resistance improvement of crop, Breeding for weeds resistance varieties development of crop, Breeding for quality crops improvement, Breeding for quality protein content improvement of crop and Breeding for increasing grain and biomass yield of crop(Arnel ., 2011; Bernardo., 2002)

Among different objective of plant breeding the most one that are plant breeder currently progress are breeding for drought tolerance crop verity development for different type of crop because of drought is the single largest a biotic stress factor leading to reduced crop yields. In general approximately onethird of the Earth's land area is arid or semi-arid and badly affecting the crop productivity and its accounting for about 70\% reductions in yield of our total cereal crops (Mueen et al., 2013; Hussain et al., 2011; Boyer., 1982; Liang., 2016)

Based on agriculture point of view the simplest definition of drought is a situation when the water availability to plant or crop is less than what the plant or crop is required to sustain its growth and development. The definition of drought tolerance is the ability of the plant or crop to survive in water limited conditions or environment. However, inducing drought tolerance in crop plants is not a simple task rather one of the most difficult challenges currently the breeders face. Because of due to its polygenic nature of drought that means drought is genetically control by many genes with low heritability and high $\mathrm{G} \times \mathrm{E}$ interactions (Deikman et al., 2011; Turner, 1979; Fleury et al., 2010)

The polygenic complex nature and the lack of proper understanding of the underlying mechanisms of drought tolerance in crop breeding are make slow progress in improving the yield of crops in drought prone environments (Tuberosa and Salvi, 2006; Cattivelli et al., 2008).

Without any interference of mankind and any kind of technology Plants have different mechanisms to survive drought in different environment by themselves the most one that plants use to survive 
drought are plants use the escape strategy through accelerating flowering before the onset of drought season, improve the water use efficiency (WUE) through closing stomata and increasing root development and plants use some tolerance mechanisms such as osmotic adjustment and production of antioxidants but steel there is no unified or effective drought tolerance mechanism at the whole plant or gene level. (Deikman et al., 2011; Gowda et al., 2011; Umezawa et al., 2006; Blum., 2004)

Water availability is particularly critical for agricultural crops to maintain high yields in variable growing seasons. Thus, agricultural drought, namely water deficiency, adversely affects plant and crop production by reducing leaf size, stem extension and root proliferation, disturbing plant water and nutrient relations, and inhibiting water-use efficiency (Liang, 2016; Chaves, 2003).

Drought is currently the leading threat to the world's food security. At the same time, it is a big challenge to achieve an average annual increase in cereal production of 44 million metric tons per year for meeting the demand of 9 billion people by 2050; h so developing drought tolerant crops may become a factor to maintain plant growth and productivity because of drought tolerant crops can be grown in areas where other crops cannot easily grow, thereby sustaining and potentially expanding the area for agricultural production (FAO U, 2009; Liang, 2016).

In this review focused the objective to summaries breeding for drought tolerance an overview on the methodology or approaches that are many countries and international organizations use to develop drought tolerance and water saving crop variety in breeding system or program for in inducing general various type of crops both in conventional and modern biotechnology tool with their basic principles that support breeding program such as marker assisted selection, transgenic approaches and modern genomic tools.

\section{The ConcePt ANd Mechanism of Drought Tolerance}

Conceptually the meaning of drought is a sustained period of time without significant rainfall that are not satisfy the need of living organism requirement specially plant for their growth and development, however. Rainfall deficit does not constitute drought in a crop production system until the water scarcity begins to limit the growth and development of crop plants (Linsley et al., 1959; Quizenberry, 1982).

Drought tolerance is collectively define as the adaptive mechanisms by which plants survive drought in different environment ant it can be grouped into three different categories that have different meaning use by plant those are, drought escape, drought avoidance and drought tolerance. However, most of crop plant are use of more than one mechanism at a time to tolerate or survive drought and we can explain the meaning of each them respectively bellow (Kumar et al.2012; Jones et al., 1980; Leonardis et al., 2012).

\subsection{Drought Escape}

is the ability of a crop plant that can complete their life cycle before development of serious problem of soil and plant water deficits at particular environment and time. This mechanism involves that plants develop rapidly phonological development to finishes their life cycle before drought are happen the most mechanism are include early flowering and maturity, variation in duration of growth period depending on the extent of water scarcity.(Hall, 2004; Mitra., 2001).

\subsection{Drought Avoidance}

Is the ability of a crop to endure or survive periods without significant rainfall even as maintaining a high plant status at high plant water potential, In other way, it is the ability of plants to maintain relatively high tissue water potential despite a shortage of soil moisture (Krammer, 1980; Mitra, 2001).

\subsection{Drought Tolerance}

The ability of a crop to endure moisture deficits at low tissue water potential or dehydration tolerance (Aazami et al., 2010).

\section{BREEDING APPROACH FOR DROUGHT TOLERANCE}

Based on the approach or methodology that the breeder use there tow type of plant breeding approach such as conventional plant breading which are use morphological or phenotypic trait to select tolerate plant or crop and Biotechnological approach/ molecular or modern approach that are focuses on at the gene level by using Biotechnology tool for identification of the gene that coded the drought tolerance 
trait and where the gene found on the chromosome are the most one methodology that the researcher or breeder use to develop drought tolerance crop(Mueen et al., 2013; Liang., 2016; Araus et al., 2008)

\subsection{Conventional Breeding Approach for Drought Tolerance}

From the beginning of plant breeding for crop improvement in last the century conventional plant breeding of crop has played a very crucial role in tackling the food productivity issues on sustainable level. The Green Revolution, occurring, was actually based on conventional plant breeding approach that leading to development of high yielding crops. The overall plant response to drought stress is quite complex involving the interaction of different component traits (primary and secondary) with the external environment and most of the drought related conventional crop breeding programs concentrate on selection strategies of those cultivars that yield well under drought stress. Commonly used conventional plant breeding methods are as follow (Araus et al., 2008; Ashraf, 2010; Rajaram, 2005).

\subsubsection{Selection Breeding Approach}

Selection breeding approach of different crop genotypes with improved drought tolerance become key issues in the world change with predicted increased frequency of droughts so based on these we have to be consider the following crucial crop phenotype for successful selection breeding such as morphological and physiological plant traits must be considered (Simova et al., 2016).

\section{Root Morphology and Physiology}

Root morphology are the first plant organ that affects by drought by means of heat waves affect directly the shoot, while roots, being in direct contact with the drying soil, transmitting the stress signal to the whole plant. The water potential in the soil declines during a drought period, but there may be considerable differences in the vertical (depth) and in the horizontal (patchiness) direction Since strong vertical gradients for soil water potential are very likely, rooting depth must be a key parameter (Bollig \& Feller., 2014; Signarbieux \& Feller, 2012; Kashiwagi et al., 2015)

For selection breeding consider that root architecture depends on root branching as well as on the length of the various roots and is relevant for the exploration of soil regions with accessible water during a drought period. Besides species specific differences between crop plants grown under non stress conditions, the plasticity of the root system in response to changing environment should be considered when breeding for drought tolerance. Root architecture is affected by the soil water, temperature and nutrients, and additionally by soil microbial communities and microbial plant interactions. A good correlation between reduced lateral root branching and drought tolerance has been reported for maize but the "rooting depth paradigm" is questioned recently. A smaller number of longer lateral roots are found in maize genotypes with a good drought tolerance (Zhan et al., 2015; Grieder et al., 2014; Nippert et al., 2015; Clarke et al., 2015).

\section{Stem Properties and Solute Allocation Via Xylem and Phloem}

Selection breeding of plant for drought tolerance of crop by their stem properties are based on the major function of the stem for crops is the solute transport between the root system and the aerial parts. Inorganic nutrients such as nitrate, sulfate, phosphate, captions; assimilates such as amino acids or ureides deriving from assimilatory processes in roots and phytohormones such as abscisic acid representing a root-to-shoot signal are transported with the transpiration stream in the xylem to the aerial plant parts. The large series of drought effects on xylem sap composition and root-to-shoot signaling including chemical changes, physical signals such as electric or hydraulic effects and waves such as reactive oxygen species or calcium concentration From these effects it became evident that the signals for drought tolerance selection of crop (Nawaz et al., 2012; Sanchez et al., 2011; Serraj et al., 1999)

\section{Leaf Morphology and Physiology}

In the other side the leaf morphology are on aspect of to select crop that have the ability tolerate drought based on photosynthetic performance during heat and drought periods that depends on morphological and physiological leaf properties such as the thickness and the properties of the cuticle and the deposition of epicuticular waxes are relevant for the non stomatal transpiration and in some plants also the formation of a stomatal plug the most important factor to select plant for drought tolerance (Sevanto, 2014; Flexas et al., 2004) 


\subsubsection{Traits to be Improved}

the key traits that can improve by conventional breeding approach for drought tolerance are includes phenology, rapid establishment, early vigor, root density and depths, low and high temperature tolerance, root conductance, osmoregulation, low stomatal conductance, leaf posture, reflectance and duration, and sugar accumulation in stems to support later growth of yield components are important traits for breeding point of view. For the development of an improved drought tolerant high yielding variety, it is necessary that the variety should have short life span (drought escape), well-developed root system, high stomatal tolerance, high water use efficiency (drought avoidance), and increased and stabilized yield during water stress period (drought tolerance) (Kumar et al., 2012).

\subsubsection{Physiogenetic Approach}

The degree of drought stress severity can be seen on plants by symptoms and effects on physiological metabolisms and yield. Many symptoms of drought stress are clear such as leaf rolling, molding, yellowing (chlorosis), browning and wilting. At the physiological level, drought stress alters the complete physiology and metabolism of plants. The physiologically relevant indicators of drought effects are the water content and the water potential of plant tissues so depend on those septum we can select drought tolerance crop (Jones, 2007; Kadioglu et al.,2012)

\subsubsection{Mutation Breeding for Drought Stress}

One of the conventional breeding approach are for drought tolerance are mutation breeding that are use different chemicals like to cause mutation on crop genetic content and finally generate drought tolerance cultivar by high frequency of gene mutation and chromosomal alterations. Irradiation dosages between 0 and $300 \mathrm{~Gy}$ were applied in order to determine the optimal irradiation dose of 180 Gy. and physiological traits for drought stress were identified. Roots of mature plants were also assessed and the variation observed could be correlated with drought tolerance. (Ronde \& Spreeth, 2007; Gonzalez et al., 2005).

\subsection{Biotechnology/Modern Breeding Approach}

Modern approach of plant breeding such as biotechnological tool are The techniques that use for gene transformation of crop plants have been applied for identification of genes responsible for drought resistance and their transfer by different methodology listed bellow (Paro, 2017)

\subsubsection{Mapping Quantitative Trait Loci (Qtls) Associated with Drought Tolerance}

Traits which show continuous variation (polygenic) are called quantitative traits while genes behind those traits are simply referred to as QTLs. Mapping is putting genes or QTLs in order indicating relative distances among them assigning them to their linkage groups on the basis of their recombination values. Generally the mapping population is derived from crosses between closely related species differing in the drought tolerance traits. There is long standing interest in QTL mapping due to the fact that it will ultimately help us to gain insight into very basic architecture of the trait concerned. Five types of populations are generally employed for QTL mapping. These are double haploids, recombinant inbred lines (RILs), backcross populations, near isogenic lines (NILs) and F2 populations. This QTL mapping allows assessing the locations, numbers, magnitude of phenotypic effects, and pattern of gene action for drought tolerance (Vinh, 2005; Hussain, 2006)

An increasing number of QTLs related to drought response have been reported, and these include QTLs for root morphology and other root traits such as root penetration ability, osmotic adjustment, grain yield and yield components, stay green, canopy temperature, leaf rolling and leaf drying (Yue et al., 2006; Price et al., 2002; Babu et al., 2003; Lafitte et al., 2004; Xu et al., 2005; Jiang et al., 2004)

\subsubsection{Marker-Assisted Selection}

Marker assisted breeding program to improve crop for drought resistance is accomplished through selection for yield and because of low heritability of yield under stress and the spatial as well as temporal variation in the field environment, conventional breeding approaches are slow. Whereas molecular markers such as single sequence repeat (SSR) and single nucleotide polymorphism (SNP) are facilitate to develop drought-resistant genotypes more effectively as their expressions are independent of environmental effects. After identification of the molecular markers associated with yield or other morphological traits related to drought resistance, those markers could be used as 
selection criteria for drought resistance. The application of marker-assisted selection in evolving drought resistant genotypes is in an experimental stage; more specifically just identification of RFLP markers associated with osmotic adjustment, stay green, root traits(Ghafoor., 2012; Jiang et al., 2004)

Drought tolerance characters are quantitative in nature; the complete genetic dissection of these complex traits into component genetic factors is a preliminary task. Therefore molecular genetic markers offer a great opportunity of locating the QTLs controlling these traits. These molecular markers are very powerful as these remain unaffected by the external environment. Once it is ensured that these markers are tightly linked and tagged with a QTL concerned, selection at early segregating generation can be pursued (Khan, 2012; Manickavelu et al., 2006)

\subsubsection{Genetic Engineering}

The identification of candidate genes is critical for our understanding of molecular and physiological mechanisms of drought tolerance in crops, as it will enable us to use transgenic approaches in breeding for abiotic stress tolerance. A transgenic approach is one that involves some structural modifications in traits through gene transfers from one species to the other. As the regulatory networks underlying the abiotic stress responses are being fully understood, more and more candidate genes will be identified to be used in development of transgenic plants. A detailed description of drought tolerance genes can be found in the review of Hadiarto and Tran (2011). A number of such genes associated with drought tolerance have been identified. Like transcription factors that up regulate and down regulate the expression of other genes (Dolferus et al., 2011; Ashraf, 2010; Barnabás et al., 2008)

\subsubsection{OMIC Technologies for Drought Tolerance}

The applications of omics type technologies are beginning to have an impact in enhancing our understanding of plant's responses towards external environmental stimuli such as drought. The term "omics" is a blend of high throughput genomics, proteomics (analysis of protein complement) and metabolomics approaches. The generation of expressed sequence tags (ESTs) from cDNA libraries and complete genome sequence information in Arabidopsis and rice provide valuable information about gene discovery that helps for identification of drought tolerance crop (Sreenivasulu et al., 2007; Houde et al., 2006)

\section{CONCLuSion}

Considering the importance of crop plants as a predominant source of food around the world, identification of traits and genotypes associated with drought tolerance is absolutely necessary. Concerted efforts are required to fully understand the physiological and genetic basis of drought tolerance. Focus should be on screening resistant germplasm and discovering potential candidate genes. Characterization and mapping of such genes at the physiological and molecular level will be key factors in the application of conventional breeding approach and molecular marker technology to the development of more drought tolerant cultivars. Biotechnology tools such as Transgenic and omics based technologies have been shown to be powerful tools holding a tremendous promise for the future. However, these approaches need to be fine-tuned and their significance at the controlled and field conditions need be fully assessed. Surely, the new Biotechnology tool such as genomic tools will enhance but not replace the conventional breeding and selection process. An interdisciplinary approach combining the knowledge of plant breeders, crop physiologists, biotechnologist and molecular biologists would be most appropriate to study and evaluate the complex plant responses to develop drought tolerant in crops.

\section{REFERENCES}

[1] Aazami MA, Torabi M and Jalili E. 2010. In vitro response of promising tomato genotypes for tolerance to osmotic stress.Afr. J. Biotech. 9(26): 4014-4017.

[2] Araus J. L., Slafer G. A., Royo C., Serret M. D. 2008. Breeding for yield potential and stress adaptation in cereals. Critical Reviews in Plant Science, 27: 377-412

[3] Araus J. L., Slafer G. A., Royo C., Serret M. D. 2008. Breeding for yield potential and stress adaptation in cereals. Critical Reviews in Plant Science, 27: 377-412

[4] Ashraf M. 2010. Inducing drought tolerance in plants: Recent advances. Biotechnology Advances, 28 (1): 169-183

[5] Ashraf M. 2010. Inducing drought tolerance in plants: Recent advances. Biotechnology Advances, 28 (1): $169-183$ 
[6] Babu R. C., Nguyen B. D., Chamarerk V., Shanmugasundaram P.,Chezhian P., Jeyaprakash P., Ganesh S. K., Palchamy A.,Sadasivam S., Sarkarung S., Wade L. J., Nguyen H. T.2003. Genetic analysis of drought resistance in rice by molecular markers: association between secondary traits and field performance. Crop Science, 43: 1457-1469.

[7] Barnabás B., Jäger K., Fehér A. 2008. The effect of drought and heat stress on reproductive processes in cereals. Plant, Cell and Environment, 31: 11-38

[8] Bernardo R., 2002. Breeding for quantitative traits. Stemma Press, Minneapolis, 400p.

[9] Blum A. 2004. The physiological foundation of crop breeding for stress environments. Proceedings of the World Rice Research Conference. Tsukuba, Japan, p. 456-458

[10] Bollig, C.; Feller, U. 2014. Impacts of drought stress on water relations and carbon assimilation in grassland species at different altitudes. Agric. Ecosyst. Environ., 188, 212-220.

[11] Boyer J. S. 1982. Plant productivity and environment. Science, 218: 443-448

[12] Cattivelli L., Rizza F., Badeck F. W., Mazzucotelli E.,Mastrangelo A. M., Francia E., Mare C., Tondelli A.,Stanca A. M. 2008. Drought tolerance improvement in crop plants: an integrative view from breeding to genomics.Field Crop Research, 105: 1-14

[13] Chaves MM, Maroco JP, Pereira JS., 2003. Understanding plant responses to drought-from genes to the whole plant. Funct Plant Biol 30:239-264

[14] Clarke, S.J.; Lamont, K.J.; Pan, H.Y.; Barry, L.A.; Hall, A.; Rogiers, S.Y. 2015, Spring root-zone temperature regulates root growth, nutrient uptake and shoot growth dynamics in grapevines. Aust. J. Grape Wine Res. 21,479-489.

[15] Deikman J., Petracek M., Heard J. E. 2011. Drought tolerance through biotechnology: improving translation from the laboratory to farmers' fields. Current Opinion in Biotechnology, 23: 1-8

[16] Dolferus R., Ji X., Richards R. A. 2011. Abiotic stress and control of grain number in cereals. Plant Science, 181

[17] FAO U., 2009. World summit on food security. Food and agriculture organization of the United Nations Rome

[18] Fleury D., Stephen J. S., Kuchel H., Langridge P. 2010. Genetic and genomic tools to improve drought tolerance in wheat.Journal of Experimental Botany, 61 (12): 3199-3210

[19] Flexas, J.; Bota, J.; Loreto, F.; Cornic, G.; Sharkey, T.D. 2004, Diffusive and metabolic limitations to photosynthesis under drought and salinity in C(3) plants. Biol. Plant. 6, 269-279.

[20] Ghafoor A., McPhee K. 2012. Marker assisted selection (MAS) for developing powdery mildew resistant pea cultivars. Euphytica, 186: 593-607

[21] Gonzalez Cepero MC, Mukandama JP, Fuentes JL and Alí Mansoor Mohamed.2005, induction of drought tolerance in tomato using $60 \mathrm{CO}$ gamma ray irradiation. National Institute of Agricultural Science, San José de las Lajas, Cuba. Muta. Breed. Newslett. Rev. 1: 9.

[22] Gowda V. R. P., Henry A., Yamauchi A., Shashidhar H. E., Serraj R. 2011. Root biology and genetic improvement for drought avoidance in rice. Field Crops Research, 122:1-13

[23] Grieder, C.; Trachsel, S.; Hund, A. 2014. Early vertical distribution of roots and its association with drought tolerance in tropical maize. Plant Soil, 377, 295-308.

[24] Hadiarto T., Tran L. S. P. 2011. Progress studies of droughtresponsive genes in rice. Plant Cell Reports, 30: $297-310$

[25] Hall AE. 2004. Breeding for adaptation to drought and heat in cowpea. Europ. J. Agron. 21: 447-454.

[26] Hallauer, A.R., 2011. Evolution of plant breeding. Crop breeding and applied biotechnology, 11(3), pp.197-206.

[27] Houde M., Belcaid M., Ouellet F., Danyluk J., Monroy A. F., Dryanova A., Gulick P., Bergeron A., Laroche A., Links M. G., MacCarthy L., Crosby W. L., Sarhan F. 2006. Wheat EST resources for functional genomics of abiotic stress. BMC Genomics, 7: 149

[28] Hussain S. S., Kayani M. A., Amjad M. 2011. Transcription factors as tools to engineer enhanced drought stress tolerance in plants. Biotechnology Progress, 27 (2): 297- 306

[29] Jiang G. H., He Y. Q., Xu C. G., Li X., Zhang Q. 2004. The genetic basis of stay-green in rice analysed in a population of doubled haploid lines derived from an indica by japonica cross. Theoretical and Applied Genetics, 108: 688-698

[30] Jones HG .2007, Monitoring plant and soil water status: established and novel methods revisited and their relevance to studies of drought tolerance. J. Exp. Bot. 58: 119-130.

[31] Jones MM, Osmond CB and Turner NC .1980. Accumulation of solutes in leaves of sorghum and sunflower in response to water deficits. Aust. J. Pl. Physiol. 7: 181-192. 
[32] Kadioglu Asim, Terzi Rabiye, Saruhan Neslihan and Saglam Aykut. 2012, Current advances in the investigation of leaf rolling caused by biotic and abiotic stress factors. Plant Sci. 182: 42- 48.

[33] Kashiwagi, J.; Morito, Y.; Jitsuyama, Y.; An, P.; Inoue, T.; Inagaki, M. 2015. Effects of root water uptake efficiency on soil water utilization in wheat (Triticum aestivum L.) under severe drought environments. J. Agric. Crop Sci., 201, 161-172

[34] Khan M. A. 2012. Current status of genomic based approaches to enhance drought tolerance in rice (Oryza sativa L.), an over view. Molecular Plant Breeding, 3 (1): 1-10

[35] Krammer PJ .1980. Drought resistance and the origin of adaptations of plants to water and high temperature stress Turner NC and Krammer PJ (Eds.). Wiley-Interscience,New York. 7-20 pp.

[36] Kumar, R., Solankey, S.S. and Singh, M. 2012. Breeding for drought tolerance in vegetables. Veg. Sci., 39(1): 1-15.

[37] Kumar, R., Solankey, S.S. and Singh, M., 2012. Breeding for drought tolerance in vegetables. Veg Sci, 39(1), pp.1-15.

[38] Lafitte H. R., Price A. H., Courtois B. 2004. Yield response to water deficit in an upland rice mapping population: associations among traits and genetic markers. Theoretical and Applied Genetics, 109: 12371246

[39] Leonardis AMD, Petrarulo M, Vita PD and Mastrangelo AM .2012. Genetic and molecular aspects of plant response to drought in annual crop species. In: Advances in Selected Plant Physiology Aspects, Giuseppe $\mathrm{M}$ and B Dichio (eds.). InTech Publisher. 45-74 pp.

[40] Liang, C., 2016. Genetically Modified Crops with Drought Tolerance: Achievements, Challenges, and Perspectives. In Drought Stress Tolerance in Plants, Vol 2 (pp. 531-547). Springer, Cham.

[41] Linsley RK, Kohler MA and Paulhus JLH. 1959. Appliedhydrology. McGraw-Hill, New York.

[42] Manickavelu A., Nadarajan N., Ganesh S. K., Gnanamalar R. P., Babu R. C. 2006. Drought tolerance in rice: morphological and molecular genetics consideration. Plant Growth Regulation, 50: 121-138

[43] Mitra, J., 2001. Genetics and genetic improvement of drought resistance in crop plants. Current science, pp.758-763.

[44] Mueen Alam, K.H.A.N., Iqbal, M., Akram, M., Ahmad, M., Hassan, M.W. and Jamil, M., 2013. Recent advances in molecular tool development for drought tolerance breeding in cereal crops: a review.

[45] Nawaz, F.; Ahmad, R.; Waraich, E.A.; Naeem, M.S.; Shabbir, R.N.2012, Nutrient uptake, physiological responses, and yield attributes of wheat (Triticum aestivum L.) exposed to early and late drought stress. J. Plant Nutr, 35, 961-974.

[46] Nippert, J.B.; Holdo, R.M. 2015. Challenging the maximum rooting depth paradigm in grasslands and savannas. Funct. Ecol.29, 739-745.

[47] Paroda, R. S., 2017, in Approaches for Incorporating Drought and Salinity Resistance in Crop Plants (eds Chopra, V. L. and Paroda, R. S.), Oxford and IBH, New Delhi, , pp. 87-107.

[48] Price A. H., Cairns J. E., Horton P., Jones H. G., Griffiths H.2002. Linking drought-resistance mechanisms to drought avoidance in upland rice using a QTL approach: progress and new opportunities to integrate stomatal and mesophyll responses. Journal of Experimental Botany, 53: 989-1004.

[49] Quizenberry JE.1982. Breeding for drought resistance and plant use efficiency. In: Breeding plants for less favourable environments, Christianses MN and Lewis CF) (eds.). 193-212.

[50] Rajaram S. 2005. Role of conventional plant breeding and biotechnology in future wheat production. Turkish Journal of Agriculture and Forestry, 29: 105-111

[51] Sanchez-Rodriguez, E.; Rubio-Wilhelmi, M.M.; Blasco, B.; Constan-Aguilar, C.; Romero, L.; Ruiz, J.M. 2011, Variation in the use efficiency of $\mathrm{N}$ under moderate water deficit in tomato plants (Solanum lycopersicum) differing in their tolerance to drought. Acta Physiol. Plant. 33, 1861-1865.

[52] Serraj, R.; Sinclair, T.R.; Purcell, L.C. 1999, Symbiotic N2 fixation response to drought. J. Exp. Bot., 50, $143-155$.

[53] Sevanto, S. 2014, Phloem transport and drought. J. Exp. Bot. 65, 1751-1759.

[54] Signarbieux, C.; Feller, U. 2012. Effects of an extended drought period on physiological properties of grassland species in the field. J. Plant Res. 125, 251-261. [CrossRef] [PubMed]

[55] Simova-Stoilova, L., Vassileva, V. and Feller, U., 2016. Selection and Breeding of Suitable Crop Genotypes for Drought and Heat Periods in a Changing Climate: Which Morphological and Physiological Properties Should Be Considered?. Agriculture, 6(2), p.26.

[56] Sreenivasulu N., Sopory S. K., Kavi Kishor P. B. 2007. Deciphering the regulatory mechanisms of abiotic stress tolerance in plants by genomic approaches. Gene, 388: 
[57] Tuberosa R., Salvi S. 2006. Genomics-based approaches to improve drought tolerance of crops. Trends in Plant Science, 11 (8): 405-412

[58] Turner N. C. 1979. Drought resistance and adaptation to water deficits in crop plants. Mussell H., Staples C. R.(eds). Stress physiology in crop plants. New York, USA,p. 343-372

[59] Umezawa T., Fujita M., Fujita Y., Yamaguchi-Shinozaki K.,Shinozaki K. 2006. Engineering drought tolerance in plants discovering and tailoring genes to unlock the future.Current Opinion in Biotechnology, 17: $113-122$

[60] Xu J. L., Lafitte H. R., Gao Y. M., Fu B. Y., Torres R., Li Z. K.2005. QTLs for drought escape and tolerance identified in a set of random introgression lines of rice. Theoretical and Applied Genetics, 111: $1642-1650$

[61] Yue B., Xue W., Xiong L., Yu X., Luo L., Cui K., Lin D., Xing Y.,Zhang Q. 2006. Genetic basis of drought resistance at reproductive stage in rice: separation of drought tolerance from drought avoidance. Genetics, 172: 1213-1228.

[62] Zhan, A.; Schneider, H.; Lynch, J.P. 2015. Reduced lateral root branching density improves drought tolerance in maize. Plant Physiol., 168, 1603-1615.

Citation: Birhanu Babiye, "Application of Biotechnology as a Breeding Tool in Crop Improvement for Drought Tolerances", International Journal of Research Studies in Microbiology and Biotechnology (IJRSMB),vol. 5, no. 1, pp. 32-39, 2019. Available: DOI: http://dx.doi.org/10.20431/2454-9428.050105

Copyright: () 2019 Authors. This is an open-access article distributed under the terms of the Creative Commons Attribution License, which permits unrestricted use, distribution, and reproduction in any medium, provided the original author and source are credited. 